\title{
Ergen Kızlarda Polikistik Over Sendromu: Klinik, Endokrin Ve Metabolik Bulgular
}

\author{
Polycystic Ovary Syndrome in Adolescent Girls: Clinical, Endocrinological and Metabolic Findings
}

\section{Bahar ÖZCABI ${ }^{1}$, Feride Tahmiscioğlu BUCAK ${ }^{1}$, Esma ŞENGENÇ ${ }^{1}$, Evrim SUNAMAK ${ }^{1}$ İbrahim ADALETLI ${ }^{2}$, Sebuh KURUĞOĞLU ${ }^{2}$, Oya ERCAN ${ }^{1}$, Olcay EVLIYAOĞLU ${ }^{1}$}

1. Istanbul Ünv. Cerrahpaşa Tıp Fakültesi, Çocuk Sağllğı ve Hast. Anabilim Dalı, Çocuk Endokrinoloji B.D., Istanbul, Türkiye 2. İstanbul Üniversitesi Cerrahpaşa Tip Fakültesi, Radyoloji Anabilim Dall, İstanbul, Türkiye

\section{$\ddot{O Z Z E T}$}

Amaç: Polikistik over sendromu tanısı alan ergen kızların basvurudaki klinik, metabolik ve endokrin bulgularını değerlendirmeyi amaçladık.

Gereçler ve Yöntem: Ocak 2008-Aralık 2012 tarihleri arasında Rotterdam tanı ölçütlerine göre tanılandırılan 53 olgunun yakınmaları, adet düzenleri, fizik bakı bulguları (antropometrik ölçümler, Ferriman Gallwey skoru, akantozis nigrikans varlı$\breve{g}$ ), bazal/uyarılmış adrenal androjen, açlık glukoz/insülin degerleri, kan yă ve lipoprotein düzeyleri, pelvik ultrasonografi bulguları kaydedildi. Yaşa göre vücut kitle indeksi (VKI) \%95 ve üzeri olgular şişman olarak tanımlandl. Oligo/amenore, hiperandrojenizm ve ultrasonografide polikistik over bulgulartnın hepsinin bulunduğu hastalar klasik grup olarak adlandlrıldr. Kan trigliserit düzeyi yașa göre $\% 97$ değerinden fazla ise yüksek olarak nitelendirildi; HOMA-IR değeri $\geq 3,82$ olgularda insülin direnci var kabul edildi.

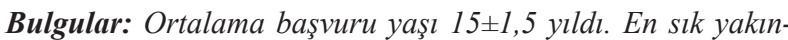
ma adet düzensizliğiydi $(\% 49,1)$. Adet düzeni ayrintıl sorgulandiğındaysa olguların \%60,4'ünde oligo/amenore olduğu görüldü. Olguların \%43,4'ü sismand. Akantozis nigrikans $(\% 37,7)$ olan olgularda şişmanlık daha sıktı $(p=0.010)$. Hirsutizm \%41,5 olguda orta-ăgır (Ferriman Gallwey skoru $\geq 16$ ) olarak belirlendi: orta-ăğr olgularda oligo/amenore daha siktı $(p=0,007)$. Insülin direnci $\% 39,6$ olguda (\%81 obez) vardl ve akantozis nigrikans saptananlarda daha siktı $(p=0,001)$. Trigliserit yüksekligi 49 olgudan 7'sinde saptandi; bu olgulartn hepsinde insülin direnci de mevcuttu $(p=0,033)$. Serum trigliserit düzeyi ile HOMA-IR değeri arasinda korelasyon saptand $(r: 0,415)$. Polikistik over bulgusu olgularm \% 96,2 sinde belirlendi. Klasik grupta diğer gruba göre oligo/amenore, hirsutizm, akantozis nigrikans, trigliserit yüksekliği anlaml $(p<0.005)$, total testosteron düzeyi anlamlılığa yakın yüksekti $(p=0.056)$.

Sonuç: Polikistik over sendromu tanisinda adet düzeni ayrıntılı olarak sorgulanmalıdır. Akantozis nigrikans saptanan olgular insülin direnci açısından irdelenmeli, insülin direnci varlığında trigliserit yüksekliği araştırılmalıdır.

Anahtar Kelimeler: akantozis nigrikans, hiperandrojenizm, hirsutizm, insülin direnci, polikistik over sendromu

\section{ABSTRACT}

Objective: We aimed to evaluate the clinical, metabolic, and endocrinological findings of adolescent girls with polycystic ovary syndrome.

\section{İletișim}

Sorumlu Yazar: Bahar ÖZCABI

Adres: Zeynep Kamil Mahallesi, Dr. Burhanettin Üstünel Sokağ No:10, 34668 Üsküdar / İstanbul, Türkiye

Tel: +90 (505) 2477118

E-Posta: taskinbahar79@yahoo.com

Makale Geliș: 20.12.2018

Makale Kabul: 15.10.2019

DOI: http://dx.doi.org/10.16948/zktipb.499708
Material and Methods: The data about menstrual patterns, physical examination (anthropometric measurements, Ferriman Gallwey score, acanthosis nigricans), basal/stimulated adrenal androgens, fasting glucose/insulin, lipid/lipoprotein levels, and ultrasonography findings were obtained from the medical records of 53 cases diagnosed according to Rotterdam criteria between January 2008-December 2012. Patients with body mass index (BMI) percentile $\geq 95 \%$ according to age were defined as obese. Patients meeting all of the 3 criteria (menstrual irregularity, hyperandrogenism and polycystic ovaries on ultrasound) were defined as the classical group and the rest as the other group. Blood triglyceride level more than $\% 97$ percentile level according to age is considered high; insulin resistance was considered to be present in patients with HOMA-IR $\geq 3.82$.

Results: . The mean age was $15 \pm 1.5$ years. The most common complaint was menstrual irregularity (49,1\%); oligo/amenorrhea was present in $60.4 \%$ of cases when questioned in detail. Acanthosis nigricans was more frequent in obese cases $(p=0.010)$. Moderate-severe hirsutism (Ferriman Gallwey score $\geq 16$ ) was present in $41.5 \%$ of patients in whom oligo/amenorrhea was more frequent ( $p=0.007)$. Insulin resistance was detected in $39.6 \%$ of the patients (81\% obese) and more frequent in patients with acanthosis nigricans $(p=0.001)$. Hypertriglyceridemia was determined in seven of 49 cases in which insulin resistance was significantly more frequent $(p=0.033)$. A positive correlation was detected between triglyceride and HOMA-IR levels (r:0,415). Polycystic ovary on ultrasound was detected in $96.2 \%$ of patients. In classical group; oligo/amenorrhea, hirsutism, acanthosis nigricans, and hypertriglyceridemia were more frequent than the other group $(p<0.005)$. Total testosterone level was higher in the classical group but the difference was not significant $(p=0.056)$.

Conclusion: The menstrual cycle of patients with polycystic ovary syndrome should be questioned in detail. In patients with acanthosis nigricans, insulin resistance must be considered and in the presence of insulin resistance hypertriglyceridemia should be investigated.

Keywords: acanthosis nigricans, hirsutism, hyperandrogenism, insulin resistance, polycystic ovary syndome

\section{GÍRIS}

Ergen kızlar ve kadınlarda hiperandrojenizmin en sik nedeni polikistik over sendromudur (PKOS). Kadınlarda sıklığ $\%$ 6-15 olarak bildirilmektedir (1). Birçok genetik ve çevresel etmenin PKOS gelişiminde etkisi olduğu düşünülmektedir. Perimenarşiyal dönemde başlayan ovulatuar işlev bozukluğu hiperandrojenizm, insülin direnci ve insulin yüksekliği ile ilişkilidir (2).

Olgularımız, izlendikleri dönemde 2003 Rotterdam ölçütlerine göre tanı almışlardır. Bu uzlaşı raporuna göre PKOS tanısı için bildirilen 3 temel belirteçten ikisinin bulunması yeterlidir: 
1) Oligo/anovulasyon

2) Hiperandrojenizmin klinik ve/veya laboratuvar bulgusu

3) Ultrasonografide polikistik overler (bir overde 2-9 mm çapında periferik dizilimli 12 veya daha fazla follikül bulunması ve/veya over hacminin 10 ml'den büyük olması)

Ancak bu tanı için diğer hiperandrojenizm nedenleri (prolaktin yüksekliği, tiroid hastalı̆̆ı, geç başlangıçlı doğumsal adrenal hiperplazi, Cushing sendromu, vs) dişlanmalıdır (3). Bununla birlikte ergenlik döneminde PKOS'un ultrasonografik bulguları özellikle adet başlangıcının ilk iki yılında da bulunabileceğinden, bu çağdaki kız çocukları için yeni ölçütler tanımlanmaya çalışılmıştır $(4,5)$.

Tanı ölçütleri içine alınmasa da insülin direnci ve yüksekliği bu olgularda önemli bir sağlık sorunudur $(1,3,5)$. İnsülin overde androjen yapımını çeşitli mekanizmalar ile uyarır. Ayrıca insülin metabolizmasındaki bozukluk uzun dönemde kan yağlarında bozukluk, glukoz intoleransı ve şişmanlığa yol açarak kalp damar hastalıklarına da zemin hazırlar (2).

Polikistik over sendromu olan ergenlerde serum androjen düzeyleri yüksek saptanabilir. Olguların \%80'inde androjen kaynağ1 overdir ve bu durum işlevsel (fonksiyonel) overe bağlı hiperandrojenizm (FOH) olarak adlandırılır $(6,7)$.

Çalışmamızda PKOS tanısı alan ergen kızların başvurudaki klinik, laboratuvar ve radyolojik bulgularının araştırılması amaçlanmıştır.

\section{GEREÇ ve YÖNTEM}

\section{1) Olgu seçimi:}

Çalışmamıza Ocak 2008-Aralık 2012 tarihleri arasında polikliniğimize başvurmuş, 12-18 yaş aralığında, Rotterdam tanı ölçütlerine göre PKOS tanısı almış 53 olgu dahil edildi (3). Olgulardan üç tan belirtecine de sahip olanlar klasik grup, ikisine sahip olanlar ise diğer grup olarak adlandırıldı (8). Konjenital adrenal hiperplazi, tiroid işlev bozukluğu ve prolaktin yüksekliği (>24 ng/dl) olan olgular dişland.

\section{2) Laboratuvar ve klinik değerlendirme yön- temleri:}

Hastaların izlem dosyalarından yakınmalar1, adet düzenleri, antropometrik ölçümleri (vücut ağırlığı, boy, vücut kitle indeksi değerleri, standart sapma ve yüzdeleri) (9) ve fizik inceleme bulguları (akantozis nigrikans varlığı ve Ferriman Gallwey skoru) kaydedildi. Ferriman Gallwey (FG) skoru 16 ve üzeri olan olgular orta-ağır, altında olanlar hafif hirsutizmli olgular olarak değerlendirildi (8). Olgularda 45 günden uzun süren aralıklarla adet görme oligomenore; pubertal gelişim başlamaksızın 14 yaş ya da başlayarak 16 yaşınakadar adet görmeme birincil amenore; menarştan 18 ay sonra, düzenli adetten 6 ay sonra, oligomenore durumunda 3 adet döneminde veya ardiş1k 6 ay boyunca adet görmeme ikincil amenore olarak tanımland $1(8,10)$. Olgulardan vücut kitle indeksi (VKI) persantili \%85'ten az olanlar normal tart11, \% 85-95 olanlar fazla tartılı, \%95 ve üstü olanlar obez olarak sınıflandırıldı $(9,11)$.
Olguların bazal ve adrenokortikotropik hormon (ACTH) (tetrakosaktid $250 \mu \mathrm{g} / \mathrm{m}^{2}$ yapılarak başlangıç, 30 ve 60 . dakikalarda kan alınd1) ile uyarılmış kortizol, 17-hidroksiprogesteron (17OHP), androstenedion, dehidroepiandrosteron sülfat (DHEA-SO4) düzeyleri incelendi ve uyarılmış 17-OHP değeri için sınır değer $10 \mathrm{ng} / \mathrm{ml}$ olarak kabul edildi (8). Serum serbest T4, TSH, prolaktin, total ve serbest testosteron düzeyleri değerlendirildi. Açlık kan şekeri/insülin değerleri kaydedildi. Açlık kan şekeri $100 \mathrm{mg} / \mathrm{dl}$ 'nin altı normal kan şekeri değeri olarak yorumlandi (12). İnsülin direnci, açlık glukozu (mg/dl) x açlik insülin $(\mu \mathrm{U} / \mathrm{ml}) / 405$ formülüne göre hesaplanan HOMA-IR (homeostasis model assessment for insulin resistance) modeline göre değerlendirildi; 3,82 ve üzeri değerlere sahip olgular insülin direnci var olarak kabul edildi (13). Kan yağ ve lipoprotein değerleri incelendi; total kolesterol, LDL-kolesterol (HDL-K) ve trigliserit değerlerinin yaşa göre yüzde 97'nin üzerinde olması yüksek, HDL-kolesterol (HDL-K) değerinin yüzde 5'in altında olması düşük olarak değerlendirildi (14). Kan glukoz, yağ ve lipoprotein değerleri spektrofotometrik yöntem, hormon değerleri ise immuno-kemiluminesans yöntemi ile ölçüldü.

Pelvik ultrasonografi Toshiba applio 500, Japon cihazı ile yapıldı; bir overde 2-9 mm çapında periferik dizilimli 12 veya daha fazla follikül bulunması ve/veya over hacminin 10 ml'den büyük olmas1 polikistik over bulgusu olarak yorumland1 (3). İstatistiksel analiz:

İstatistiksel analizler için NCSS (Number Cruncher Statistical System) 2007 (Kaysville, Utah, USA) programı kullanıldı. Çalışma verileri değerlendirilirken tanımlayıcı istatistiksel metodların (ortalama, standart sapma, medyan, frekans, oran, minimum, maksimum) yanı sıra niceliksel verilerin karşılaştırılmasında normal dağılım göstermeyen parametrelerin iki grup karşılaştırmalarında Mann Whitney U testi kullanıldı. Niteliksel verilerin karŞ1laştırılmasında ise Fisher-Freeman-Halton testi, Fisher's Exact test ve Yates' Continuity Correction test (Yates' düzeltmeli Ki-kare) kullanıldı. Anlaml1l1k $\mathrm{p}<0.05$ düzeyinde değerlendirildi.

\section{3) Etik Kurul}

Calışma için İstanbul Üniversitesi Cerrahpaşa Tıp Fakültesi Etik Kurulu'ndan onay alındı (01.12.2015-381650). Olguların verileri geriye yönelik dosyalar taranarak toplandığından aydınlatılmış onam alınmamıştır.

\section{BULGULAR}

Ortalama başvuru yaşı $15 \pm 1,5$ y1l olan olguların başvuru yakınmaları sırasıyla adet düzensizliği $(\% 49,1)$, hirsutizm $(\% 41,5)$ ve ağırlık artışı $(\% 9,4)$ idi. Olgular adet düzenleri ile ilgili ayrıntılı sorgulandığında ise aslında tüm olguların \%60,4'ünde $(n=32)$ oligo/amenore olduğu görüldü.

Olguların \% 43,4'ü (n=23) obez, \%22,6's1 $(n=12)$ fazla tart1l idi. Akantozis nigrikans \%37,7 'sinde $(n=20)$, hirsutizm \% 83'ünde $(n=44)$ belirlendi. Akantozis nigrikans bulunan olguların 14'ü (\%70) obezdi; akantozis nigrikans bulunan olguların obezite sıklığ 1 , bulunmayanlara göre istatistiksel 
olarak anlamlı yüksekti $(\mathrm{p}=0.010)$. Obez olguların 14'ünde (\%61) akantozis nigrikans mevcuttu.

Oligomenore olan ve olmayan olgular arasinda VKİ ve akantozis nigrikans açısından anlamlı fark yoktu ( $>00,05)$. Hirsutizmi olan olgular arasinda $(n=44)$ orta - ağır skoru olanların \%69'unda $(n=16)$, hafif hirsutizmi olan olguların ise \%30,4'ünde $(n=7)$ oligo/amenore vardı ve orta-ağır hirsutizmi olan olgularda hafif hirsutizmli olgulara göre oligo/amenore istatistiksel olarak anlamlı derecede yüksekti $(\mathrm{p}=0,007)$.

Hirsutizmi olan olgulardan 30'u (\%68,2) obez ya da fazla tartılı iken 14 'ü $(\% 31,8)$ normal tartılı idi ancak hirsutizmi olan ve olmayan olgular arasinda VKI dağılımı, akantozis nigrikans ve HOMA-IR değerleri açısından anlamlı fark yoktu $(\mathrm{p}>0,05)$.

Olguların bazal ve ACTH ile uyarılmış serum adrenal androjenleri ve kortizol değerleri, total testosteron düzeyleri Tablo 1'de gösterilmiștir. İnsülin direnci \%39,6 $(n=21)$ olguda belirlendi. İnsulin direnci olan olguların \%81'i $(n=17)$ obez, $\% 4,7$ 'i fazla tart1lı $(\mathrm{n}=1), \% 14,3$ 'u normal tart11 $(\mathrm{n}=3)$ idi. İnsülin direnci belirlenen \%66,7 $(\mathrm{n}=14)$ olguda akantozis nigrikans saptandi. Akantozis nigrikans görülen olguların HOMA-IR değerleri, görülmeyenlere göre anlamlı derecede yüksekti $(\mathrm{p}=0.001)$ (Şekil 3). İnsülin direnci olan olguların 19'unda (\%91) hirsutizm de gözlendi, bu olguların 8'inde $(\% 42,1)$ orta-ağır hirsutizm mevcuttu.

Olguların 49'unda $(\% 92,5)$ kan lipid ve lipoprotein profili değerlendirildi. Total kolesterol yüksekliği 6 olguda $(\% 12,2)$ belirlendi: bu olgulardan sadece birinde $(\% 16,7)$ insülin direnci vard. Olguların 7'sinde $(\% 14,3)$ trigliserit yüksekliği izlendi; bu olguların 6'sında $(\% 85,7)$ insülin direnci mevcuttu. Sadece bir olguda (\%2) HDL-K düşüklügü gözlendi. Kolesterol yüksekliği olan hastalarda oligo/amenore görülme oranı istatistiksel olarak anlamlı olmasa da yüksek idi $(\mathrm{p}=0,069)$; ancak kolesterol yüksekliği olan ve olmayanlar arasında insülin direnci, obezite/fazla tartılılık ve hirsutizm açısından fark yoktu $(\mathrm{p}>0,05)$. Trigliserit düzeyi yüksek olan ve olmayan olgular arasinda oligo/amenore, hirsutizm varlığı ve VKİ değeri açısından fark yok iken $(\mathrm{p}>0,05)$, insülin direnci varlığ 1 istatistiksel olarak anlamli derecede $\mathrm{s} 1 \mathrm{kt}(\mathrm{p}=0,033)$. Serum trigliserit düzeyi ile HOMA-IR değeri arasında doğru orantı belirlendi (r: 0,415).

Polikistik over (PKO) bulgusu ultrasonografik olarak olguların \% 96,2'sinde $(n=51)$ belirlendi.

Olgular klasik grup ve diğer grup olarak ikiye ayrıldı (8). Olguların bu gruplara göre değerlendirilmeleri Tablo 2'de özetlenmiştir. Klasik grupta oligo/amenore $(p=0.001)$, hirsutizm $(p=0.008)$, akantozis nigrikans $(\mathrm{p}=0.038)$ varlığ 1 ve trigliserit yüksekliği $(\mathrm{p}=0.033)$ daha s1kt1. Klasik grupta serum total testosteron düzeyi istatistiksel olarak anlamlı olmamakla birlikte diğer gruba göre yüksekti $(\mathrm{p}=0.056)$.

Gruplar arasında bazal ve doruk DHEA-SO4 ile 1,4 androstenedion ölçümleri arasında istatistiksel olarak anlamlı farklılık saptanmad1 ( $\mathrm{p}>0,05)$. HOMA-IR değerleri kıyaslandığında klasik PKOS ve diğer gruplar arasında istatistiksel olarak anlamlı farklılık saptanmadi $(\mathrm{p}>0,05)$.
Tablo 1: Olguların bazal ve uyarılmış serum adrenal androjen, kortizol ve total testosteron düzeyleri.

\begin{tabular}{|c|c|c|}
\hline & $\begin{array}{l}\text { Min-Mak } \\
\text { (Medyan) }\end{array}$ & Ort \pm Ss \\
\hline $\begin{array}{l}\text { Kortizol } \mu \mathrm{g} / \mathrm{dl} \\
\text { (bazal / uyarılmış) }\end{array}$ & $\begin{array}{l}2,7-35(14,1) \\
18-59,8(30,5)\end{array}$ & $\begin{array}{l}14,3 \pm 7,1 \\
32,93 \pm 8,68\end{array}$ \\
\hline $\begin{array}{l}\text { 17-hidroksiprogesteron } \\
\text { ng/ml (bazal / uyarılmış) }\end{array}$ & $\begin{array}{l}0,2-5,8(1,3) \\
1,3-9,6(3,7)\end{array}$ & $\begin{array}{l}1,70 \pm 1,26 \\
3,97 \pm 1,91\end{array}$ \\
\hline $\begin{array}{l}\text { DHEA-S04 } \mu \mathrm{g} / \mathrm{ml} \\
\text { (bazal/ uyarılmış) }\end{array}$ & $\begin{array}{l}52,2-650(280) \\
62,5-644(137,2)\end{array}$ & $\begin{array}{l}308,91 \pm 136,39 \\
341,42 \pm 144,9\end{array}$ \\
\hline $\begin{array}{l}\text { 1,4 androstenedion } \mathrm{ng} / \mathrm{dl} \\
\text { (bazal/uyarılmış) }\end{array}$ & $0,1-6(2,5)$ & $\begin{array}{l}2,56 \pm 1,05 \\
3,54 \pm 1,48\end{array}$ \\
\hline $\begin{array}{l}\text { Bazal total testosteron } \\
\text { ng/dl }\end{array}$ & $3,1-194(66)$ & $70,45 \pm 43,12$ \\
\hline
\end{tabular}

DHEA-SO4: dehidroepiandrostenedion sülfat

Tablo 2: PKOS gruplarının klinik ve laboratuvar karşılaştırmaları.

\begin{tabular}{|c|c|c|c|c|}
\hline & & \multicolumn{2}{|c|}{ PKOS grubu } & \multirow{3}{*}{$\mathrm{P}$} \\
\hline & & \multirow{2}{*}{$\begin{array}{c}\text { Klasik }(\mathrm{n}=21) \\
\mathrm{n}(\%)\end{array}$} & \multirow{2}{*}{\begin{tabular}{|c|} 
Diğer $(n=32)$ \\
$n(\%)$
\end{tabular}} & \\
\hline & & & & \\
\hline \multirow{2}{*}{$\begin{array}{l}\text { Akantozis } \\
\text { nigrikans }\end{array}$} & Yok & $9(42,9)$ & $24(75,0)$ & \multirow[t]{2}{*}{ b0,038* } \\
\hline & Var & $12(57,1)$ & $8(25,0)$ & \\
\hline \multirow{2}{*}{ Hirsutizm } & Yok & $0(0)$ & $9(28,1)$ & \multirow{2}{*}{$0,008 * *$} \\
\hline & Var & $21(100)$ & $23(71,9)$ & \\
\hline \multirow{2}{*}{ Oligo/amenore } & Yok & $0(0)$ & $21(65,6)$ & \multirow{2}{*}{$\mathrm{b} 0,001 * *$} \\
\hline & Var & $21(100)$ & $11(34,4)$ & \\
\hline \multirow{2}{*}{ Total Kolesterol } & normal & $16(76,2)$ & $27(96,4)$ & \multirow{2}{*}{0,072} \\
\hline & yüksek & $5(23,8)$ & $1(3,6)$ & \\
\hline \multirow{2}{*}{ Trigliserit (mg/dl) } & normal & $15(71,4)$ & $27(96,4)$ & \multirow{2}{*}{$0,033^{*}$} \\
\hline & yüksek & $6(28,6)$ & $1(3,6)$ & \\
\hline HOMA-IR & $\begin{array}{l}\text { Normal } \\
\text { Yüksek }\end{array}$ & $\begin{array}{l}11(52,4) \\
10(47,6)\end{array}$ & $\begin{array}{l}21(63,7) \\
11(33,3)\end{array}$ & 0,498 \\
\hline HOMA-IR & $\begin{array}{l}\text { Min-Mak } \\
\text { (Medyan) } \\
\text { Ort } \pm \text { Ss }\end{array}$ & $\begin{array}{l}1,4-13,2(3) \\
4,12 \pm 2,87\end{array}$ & $\begin{array}{l}0,95-13,5 \\
(2,7) \\
3,48 \pm 2,24\end{array}$ & $\mathrm{~d} 0,567$ \\
\hline \multirow{2}{*}{$\begin{array}{l}\text { Bazal DHEA-SO4 } \\
(\mu \mathrm{g} / \mathrm{dl})\end{array}$} & $\begin{array}{l}\text { Min-Mak } \\
\text { (Medyan) }\end{array}$ & $\begin{array}{l}52,18-650 \\
(343,4)\end{array}$ & $\begin{array}{l}134,2-578 \\
(257,5)\end{array}$ & \multirow{2}{*}{${ }^{d} 0,136$} \\
\hline & Ort \pm Ss & $344,34 \pm 160,26$ & $285,65 \pm 114,99$ & \\
\hline $\begin{array}{l}\text { Bazal } 1,4 \\
\text { Androstenedion } \\
(\mathrm{ng} / \mathrm{dl})\end{array}$ & $\begin{array}{l}\text { Min- Mak } \\
\text { (Medyan) } \\
\text { Ort } \pm \text { Ss }\end{array}$ & $\begin{array}{l}0,98-5,17 \\
(2,71) \\
2,65 \pm 0,88\end{array}$ & $\begin{array}{l}0,1-6 \\
(2,45) \\
2,5 \pm 1,15\end{array}$ & d 0,536 \\
\hline \multirow{2}{*}{$\begin{array}{l}\text { Total testosteron } \\
(\mathrm{ng} / \mathrm{dl})\end{array}$} & $\begin{array}{l}\text { Min-Mak } \\
\text { (Medyan) }\end{array}$ & $\begin{array}{l}3,10-194 \\
(86,0)\end{array}$ & $\begin{array}{l}16,60-127 \\
(56,5)\end{array}$ & \multirow[t]{2}{*}{$\mathrm{d} 0,056$} \\
\hline & Ort \pm Ss & $87,28 \pm 55,05$ & $59,04 \pm 28,42$ & \\
\hline $\begin{array}{l}\text { Uyarılmış } \\
\text { DHEA-SO4 } \\
(\mu \mathrm{g} / \mathrm{dl})\end{array}$ & $\begin{array}{l}\text { Min-Mak } \\
\text { (Medyan) } \\
\text { Ort } \pm \text { Ss }\end{array}$ & $\begin{array}{l}62,5-624,6 \\
(366,7) \\
363 \pm 163,1\end{array}$ & $\begin{array}{l}130,7-644 \\
(286,8) \\
327.3 \pm 132,5\end{array}$ & $\mathrm{~d} 0,363$ \\
\hline $\begin{array}{l}\text { Uyarılmış } 1,4 \\
\text { androstenedion } \\
(\mathrm{ng} / \mathrm{dl})\end{array}$ & $\begin{array}{l}\text { Min-Mak } \\
\text { (Medyan) } \\
\text { Ort } \pm \text { Ss }\end{array}$ & $\begin{array}{l}1,81-6,9(4,1) \\
3,94 \pm 1,52\end{array}$ & $\begin{array}{l}0,58-6,31 \\
(3,29) \\
3,29 \pm 1,42\end{array}$ & $\mathrm{~d} 0,156$ \\
\hline $\begin{array}{l}\text { Uyarılmış 17-OH } \\
\text { Progesteron } \\
(\mathrm{ng} / \mathrm{ml})\end{array}$ & $\begin{array}{l}\text { Min-Mak } \\
\text { (Medyan) } \\
\text { Ort } \pm \text { Ss }\end{array}$ & $\begin{array}{l}1,6-6,3 \\
(3,8) \\
3,68 \pm 1,41\end{array}$ & $\begin{array}{l}1,3-9,59 \\
(3,5) \\
4,15 \pm 2,18\end{array}$ & $\mathrm{~d} 0,928$ \\
\hline
\end{tabular}

b Yates' Continuity Correction Test, c Fisher's Exact Test, d Mann Whitney U Test, * $p<0,05, * * p<0,01$, VKI: vücut kitle indeksi, GnRH: Gonadotropin salg1latic1 hormon, DHEA-SO4: dehidroepiandrostenedion sülfat 


\section{TARTIŞMA}

Çalışmamızda PKOS tanısı alan ergen kızlarda en sık yakınma adet düzensizliği $(\% 49,1 \mathrm{n}=26)$ idi ancak adet düzeni irdelendiğinde oligo/amenorenin aslında olguların \%60,4'ünde $(n=32)$ mevcut olduğu görüldü. Olguların yaklaşık \%11'inde oligo/ amenore olmasına rağmen bunun sorgulanma sirasında ortaya çıkması; ergen kızların sağlık kontrolleri sırasında adet düzenin sorgulanmasının önemini ortaya koymaktadır. Bir yıldan uzun süren oligomenorenin yaklaşık \% 050 'sinin süregenlik riski taşıdığ 1 ve PKOS gelişebileceği görüşü kabul görmektedir (8). Çalışmamızda da oligo/amenore sık görülen bir sorun olarak karşımıza çıkmaktadır.

Önemli bir hiperandrojenizm bulgusu olan hirsutizm \%83 $(n=44)$ olguda saptand1. Son yillarda bazı yayınlarda ön planda orta-ağır hirsutizmi olan olgularda PKOS olasılığının düşünülmesi önerilmiştir (8). Çalışmamızda hirsutizmi olan olguların $\% 50$ 'sinde $(\mathrm{n}=22)$ orta-ağır hirsutizm belirlendi ve bu olgularda oligo/amenorenin hafif olgulara göre anlamlı düzeyde yüksek $(\mathrm{p}=0,016)$ olduğu bu yayınlara benzer şekilde gözlemlendi.

Çalıșmamızda 35 olgu $(\% 66)$ obez veya fazla tartılı idi. Bu grup ile normal ağırlıktaki grup k1yaslandığında oligo/amenore, hirsutizm, akantozis nigrikans, insülin direnci ve kan lipid/lipoprotein düzeylerinde yükseklik ( $p=0,137 ; p>0,05)$ açısından anlamlı fark saptamadik. Hiperandrojenizm bulunan ergen olgularda obezite, insülin direnci ve hiperinsülinemiye sıkça rastlanır. Her ne kadar ergenlik dönemi PKOS tanı kriterlerine eklenmesini öneren yayınlar bulunsa da 2014 y1lında yayımlanan uzlaşida obezite/fazla tartılılığın tanılandırmada belirteç olarak alınmaması, ancak sıkça eşlik eden önemli bir durum olarak kabul edilmesi gerektiği öne sürülmüştür. Çalışmamızda da benzer bir sonuç elde edilmiştir $(4,5)$.

İnsülin direnci PKOS'ta önemli bir sağlik sorunudur (7). Çalışmamızda insülin direnci HOMA-IR indeksine göre $\% 39(\mathrm{n}=21)$ olguda mevcut idi, insülin direnci saptanan \%66,7 ( $=14)$ olguda ise akantozis nigrikans gözlendi. Akantozis nigrikans görülen olguların HOMA-IR değerlerinin görülmeyenlerden anlamlı düzeyde yüksek olduğu belirlendi $(\mathrm{p}=0.001 ; \mathrm{p}<0.01)$. Buradan yola çıkarak PKOS tanılı ergen hastalarda olası insülin direnci varlığını öngörmek için akantozis nigrikansın iyi bir belirteç olduğu görüşündeyiz. Bhattacharya ve ark. (15) PKOS tanılı 49 ergen k1z olguda yaptıkları çalışmada, bulgularımıza benzer şekilde insülin direnci olanlarda akantozis nigrikans varlığının $\% 58,8$ olduğunu bildirmişler; ancak çalışmamızdan farklı olarak insülin direnci varlığını açlık glukoz/ açlık insülin oranına göre belirlemişlerdir. Çalışmamıda aynı zamanda insülin direnci olan ve olmayan olgularda serum kolesterol düzeyleri açısından bir fark saptanmamasına rağmen insulin direnci olanlarda serum trigliserit düzeyleri yüksekti. Trigliserit yüksekliği PKOS'lu kadınlarda obeziteden bağımsız olarak daha sık gözlenmiştir (16). Ayrıca PKOS tanılı kadınlarda metabolik sendrom sıklığı da artmaktadır (8). Hem kalp damar hastalıkları açısından risk yaratmaları hem de metabolik sendromun bileşenleri olmaları nedeniyle insülin direnci olan olgularda eşlik edebilecek trigliserit yüksekliğinin değerlendirilmesi takipte önem taşımaktadır $(8,14,16)$.

Olgularımızı klasik tip PKOS ve diğerleri olarak iki gruba ayırdığımızda klasik grupta hirsutizm oligo/amenore ve trigliserit yüksekliği görülme s1klıklarının daha yüksek olduğunu belirledik; bulgularımız bu gruba giren olguların daha ciddi endokrin ve metabolik bozukluklar taşıdığını göstermektedir. Her ne kadar, gruplar arasinda insülin direnci ve diğer glukoz metabolizması bozuklukları açısından bir fark bulmadiysak da, klasik grupta akantozis nigrikans görülme sıklığının daha yüksek olması bu olgularda insulin direnci açısından izlemde dikkatli olunması gerektiğini düşündürmektedir.

PKOS tanısında en sık başvuru yakınma adet düzensizliğidir ve tüm ergen kızlarda ayrıntılı olarak sorgulanmalıdır. Tanı belirteçleri arasında olmasa da obezite ve fazla tartı olguların önemli bir kısmında bulunmaktadır. Klasik PKOS olguları daha belirgin olarak endokrin ve metabolik sorunlar yaşamaktalardır o nedenle bu olgular ovariyen hiperandrojenizm, insulin, glukoz ve yağ metabolizmaları açısından yakın takip edilmelilerdir.

\section{KAYNAKLAR}

1) Fauser BC, Tarlatzis BC, Rebar RW et al. Consensus on women's health aspects of polycystic ovary syndrome (PCOS): the Amsterdam ESHRE/ASRM-Sponsored 3rd PCOS Consensus Workshop Group. Fertil Steril. 2012; 97(1), 28-38.

2) Witchel SF. Hirsutism and polycystic ovary syndrome In: Lifshitz F, editor. Pediatric Endocrinology. New York: Informa Healthcare USA Inc, 2007. P.325-48.

3) Rotterdam ESHRE/ASRM-Sponsored PCOS Consensus Workshop Group. Revised 2003 consensus on diagnostic criteria and long-term health risks related to polycystic ovary syndrome. Fertil Steril. 2004; 81(1), 19-25.

4) Sultan C, Paris F. Clinical expression of polycystic ovary syndrome in adolescent girls. Fertil Steril. 2006; 86 Suppl 1:S6.

5) Witchel SF, Oberfield S, Rosenfield RL et al. The diagnosis of polycystic ovary syndrome during adolescence. Horm Res Paediatr. 2015; 83(6), 376-389.

6) Rosenfield RL, Cooke DW, Radovick S. Puberty and it's disorders in the female. In: Sperling MA editor. Pediatric Endocrinology. Philadelphia: Saunders Elsevier. 2008;530-609.

7) Evliyaoğlu O. Polikistik over sendromu ve hirsutizm. Türk Ped Arş. 2011, 46(11).

8) Rosenfield RL. The diagnosis of polycystic ovary syndrome in adolescents. Pediatrics. 2015; 136(6):1154-65

9) Neyzi O, Bundak R, Gökçay G, Günöz H, Furman A, Darendeliler F, Baş F. Reference values for weight, height, head circumference, and body mass index in Turkish children. J Clin Res Pediatr Endocrinol. 2015;7(4):280-93.

10) Evliyaoglu $O$, Alikaşifoğlu $M$, Büyükgebiz A, Ercan O. Adolesan dönemi endokrin sorunları. In: Cinaz P, Darendeliler F, Akıncı A, Özkan B, Dündar B, Abacı A, Akçay T, editors. Çocuk Endokrinolojisi. Istanbul: Nobel Tip Kitabevleri; 2014.p.179-202.

11) Kumar S, Kelly A.S. Review of Childhood Obesity: From Epidemiology, Etiology, and Comorbidities to Clinical Assessment and Treatment. In: Mayo Clin Proc. Elsevier. 2017; 92(2):251-265.

12) Craig ME, Jefferies C, Dabelea D et al. Definition, epidemiology, and classification of diabetes in children and adolescents. Pediatr Diabetes 2014; 15(Suppl 20), 4-17.

13) Keskin M, Kondolot M. Insulin resistance in obese children and adolescents: HOMA-IR cut-off levels in the prepubertal and pubertal periods. J Clin Res Ped Endo. 2010; 2(3), 100-106.

14) Daniels, SR, Greer FR. Lipid screening and cardiovascular health in childhood. Pediatrics. 2008; 122(1), 198-208.

15) Bhattacharya SM, Ghosh M. Insulin resistance and adolescent girls with polycystic ovary syndrome. J Pediatr Adolesc Gynecol. 2010;23(3):158-6

16) Rocha MP, Marcondes JA, Barcellos CR et al. Dyslipidemia in women with polycystic ovary syndrome: incidence, pattern and predictors. Gynecol Endocrinol. 2011; 27(10), 814-819. 